\title{
CITY THREAD
}

\section{MOLLY HUNKER}

Syracuse University

CITY THREAD is the winner of the Passageways 2.0 international design competition which asks architects to create a vibrant public space in an unused alley in downtown Chattanooga TN. The project is part of an initiative sponsor by River City Company, a local non-profit developer, to revitalize and catalyze the downtown innovation district. The project creates a space that builds upon the legacy of Chattanooga and the character of downtown by extending the attitude of adventure and exploration that the "Scenic City" is known for and bring a sense of discovery and stimulation to this unused downtown space. Given the immediate context of downtown - a growing community of innovators - the projects is a social connector where the different actors of the city can come together for both unique public programming and informal hangout. Situated in a city that privileges how infrastructure can enhance urban life, our project is intended to operate as a piece of artistic infrastructure rather than simply a work of art.

The project consists of a continuous linear volume constructed from a series of large, simple steel tubes to allow for generically specific space and formal gestures. By virtue of its geometry and formal manifestation, the project possesses many potential conditions including informal lounging/sitting, mini-stages, framing community murals or art, large gatherings, farmers markets, and movie screenings, among others. Further, the zig-zagging linear structure implies a variety of smaller spaces within the alley, breaking down the overall space into a series of more intimate spaces, or "urban rooms," which are reinforced by a system of painted graphic shapes onto the alley surfaces.

From a design standpoint, the competition format (open, multi-phase) and the jury of diverse stakeholders required that we consider our approach to design differently than other projects. We needed to present a project that had wide appeal, something that was specific and clear but also ambiguous, malleable, and accessible to the numerous parties involved private, public, municipal). Given the nature of a simple formal vocabulary, the project is adaptable to a number of situations and was capable of being calibrated specifically to the site conditions (unknown at the time or proposal) and the stakeholder requirements in the design development phase.

\section{GREGORY CORSO}

Syracuse University

From a studio trajectory standpoint, this was the third consecutive competition win (at the type/scale of pavilion) of our studio and the first opportunity to produce a permanent project. The project is the most recent manifestation of specific design-based research that has been explored entirely through these recent competitions and nurtured by not being beholden to a specific client input early on. The nature of this competition and the preceding ones inherently requires that the organizers role is that of an advocate (they chose it) rather than a reluctant collaborator, thus yielding a more compelling public project. 
CITY THREAD ${ }_{\substack{\text { PASSAGEWAYS } 2.0 \text { competition } \\ \text { WINIING ENTRY }}}$

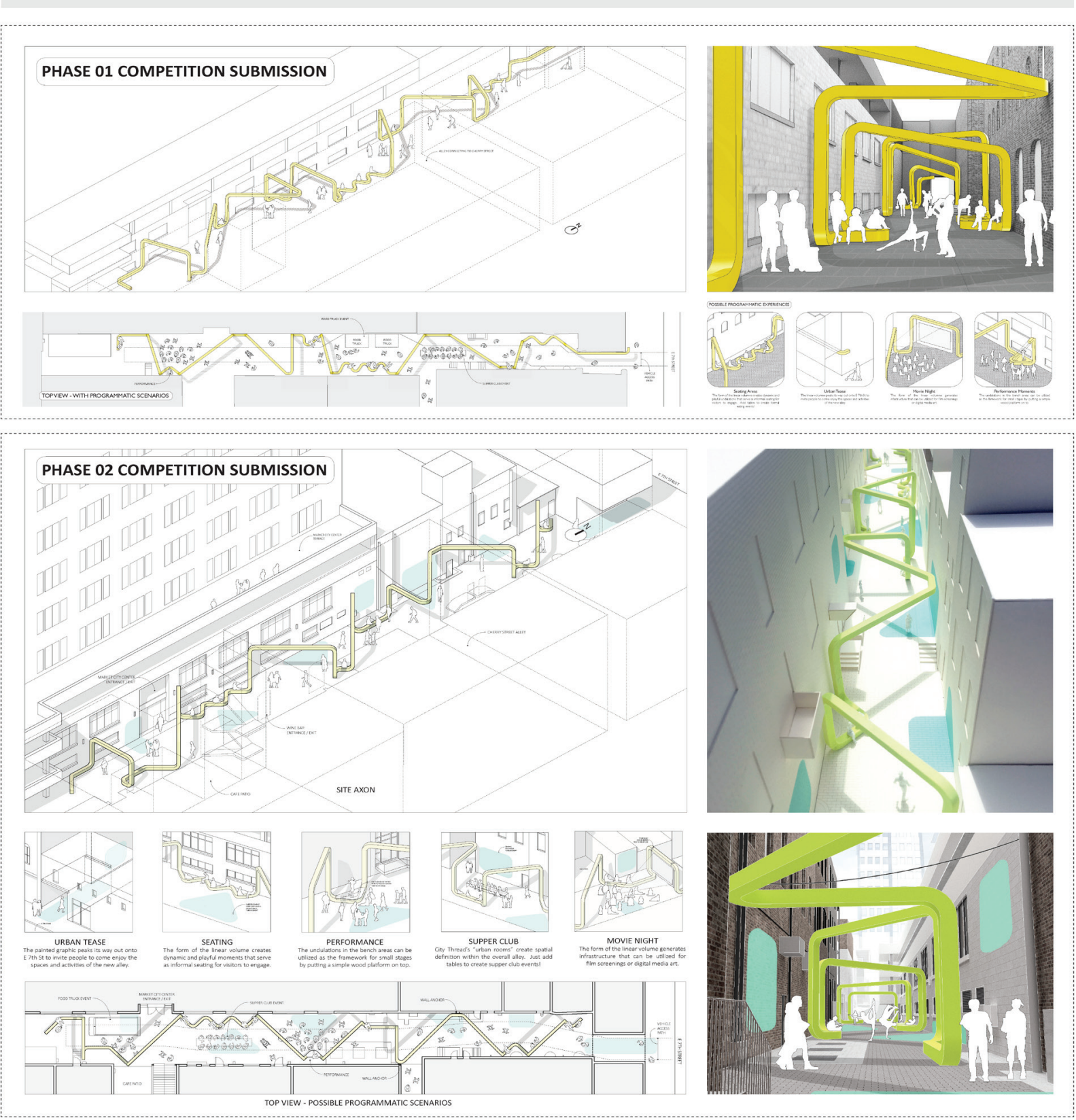

CONSTRUCTION (TO BE COMPLETED NOV 2018)
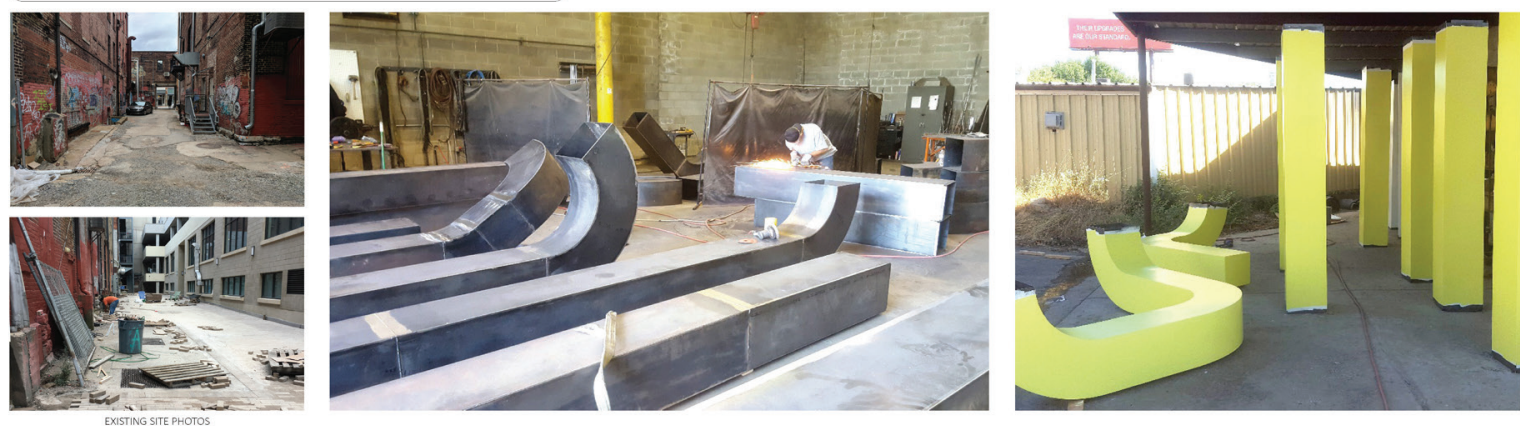